\title{
ヨウ化銀系超イオン伝導ガラスの転移領域における粘性挙動と熱的性質
}

\author{
李 相基・辰巳砂昌弘・南 努 \\ 大阪府立大学工学部機能物質科学科, 593 大阪府堺市学園町 1-1

\section{Transformation-Range Viscosities and Thermal Properties of Agl-Based Superionic Glasses} \\ Sang-Ki LEE, Masahiro TATSUMISAGO and Tsutomu MINAMI \\ Department of Applied Materials Science, College of Engineering, Osaka Prefecture University, 1-1, Gakuencho, Sakai-shi, Osaka

[Received July 23, 1993; Accepted October 7, 1993]

Differential scanning calorimetric measurements were performed for the superionic glasses in the systems $\mathrm{AgI}-\mathrm{Ag}_{2} \mathrm{O}-\mathrm{M}_{x} \mathrm{O}_{y}\left(\mathrm{M}_{x} \mathrm{O}_{y}=\mathrm{B}_{2} \mathrm{O}_{3}, \quad \mathrm{GeO}_{2}, \quad \mathbb{P}_{2} \mathrm{O}_{5}, \quad \mathrm{MoO}_{3}\right)$. Since the heat capacity change $\left(\Delta C_{p}\right)$ in glass transition was decreased with an increase in the $\mathrm{AgI}$ content in all of the systems, the fragility seemed superficially to be decreased with the $\mathrm{AgI}$ content from a viewpoint of $\Delta C_{\mathrm{p}}$. Transformation-range viscosities were also measured for the same glasses above by using a beambending method. The fragility was not changed with an increase in the AgI content from a viewpoint of $\mathbb{E \eta}$ / $T_{\mathrm{g}}$, where $E \eta$ and $\mathbb{T}_{\mathrm{g}}$ are respectively the activation energy for viscous flow and the glass transition temperature. It is thus concluded that only network part in the glass structure contributes to the value of $\Delta C_{\mathrm{p}}$ and thus the decrease of $\Delta C_{\mathrm{p}}$ with increasing $\mathrm{AgI}$ content is caused by the fact that the portion of the glass network is decreased with increasing AgI content.

Key-words : Superionic conductor, AgI-based glass, Glass transition temperature, Viscosity, Heat capacity, Fragility

\section{1. 緒言}

AgI 系超イオン伝導ガラスは，室温で $10^{-3} \sim 10^{-2}$ $\mathrm{S} \cdot \mathrm{cm}^{-1}$ という電解質溶液に匹敵するほどの高いイオン伝 導性を示すことから，全固体電池や表示素子への応用が期 待されて活発に研究が行われている1) 3)。この AgI 系超 イオン伝導ガラスの熱的性質に関してはこれまで多くの報 告があり，いずれの系においても AgI 含量が増加するほ どガラス転移温度 $\left(T_{\mathrm{g}}\right)$ が減少する傾向のあることが知 られている4) 6). 更に, 最近ガラス転移に伴う比熱の変 化量 $\left(\Delta C_{\mathrm{p}}\right)$ が $\mathrm{AgI}$ 含量の増加に伴い減少する傾向があ ることが報告された5) 7).

一方，無機，有機，高分子，低分子を問わず，多くのガ ラス性液体に対して, 温度をガラス転移温度 $\left(T_{\mathrm{g}}\right)$ で規 格化し, 広い温度域にわたって粘度の温度依存性を示した プロットは, Arrhenius 的なものと, 非 Arrhenius 的なも のに分類できる ${ }^{8)}$. 図 1 は両者のガラス性液体の粘度の温 度依存性を模式的に示したものである。一般に，ガラス転 移に伴う比熱の変化量 $\left(\Delta C_{\mathrm{p}}\right)$ の小さいガラス性液体は粘 度の温度依存性が Arrhenius 的になり，このような物質
は strong な液体と呼ばれる。一方， $\Delta C_{\mathrm{p}}$ の大きいガラス 性液体は粘度の温度依存性が非 Arrhenius 的であり, こ のような物質は fragile な液体と呼ばれる8)。このように 熱分析における $\Delta C_{\mathrm{p}}$ 及び粘度の温度依存性における非 Arrhenius 性が fragility の尺度になる。

また，図 1 に示すように， $\log \eta$ と $1 / T$ との関係は，ガ ラスの粘度を広い温度範囲にわたって測定すると直線関係 を満足しないが，ガラス転移温度付近の狭い温度域では， Arrhenius 式を満足し直線関係が成立することが知られて (る9)。 また，温度無限大での極限粘度は，本研究で取り 扱った系では組成によらずほぼ一定と考えられる。した がって, ガラス転移温度付近での粘性流動の活性化エネル ギーをEnとすると図 1 でArrhenius 的な系はガラス転移 点付近に书ける直線の傾き $E \eta / T_{\mathrm{g}}$ が小さくなり，逆に非 Arrhenius 的な系は $T_{\mathrm{g}}$ 付近に抢ける直線の傾き $E \eta / T_{\mathrm{g}}$ が 大きくなる。このように $E \eta / T_{\mathrm{g}}$ は粘度の温度依存性にお ける非Arrhenius 性とよく対応して抢り，非Arrhenius 性の尺度，すなわち fragility の尺度として用いることが できる。

前報では $\mathrm{Na}_{2} \mathrm{O}-\mathrm{SiO}_{2}$ 系ガラスに対して，組成を変化さ せた際の $\Delta C_{\mathrm{p}}$ と $E \eta / T_{\mathrm{g}}$ の変化について検討した10)。その 結果, $\mathrm{Na}_{2} \mathrm{O}$ 含量の增加に伴い $\Delta C_{\mathrm{p}}$ 及び $E \eta / T_{\mathrm{g}}$ がともに

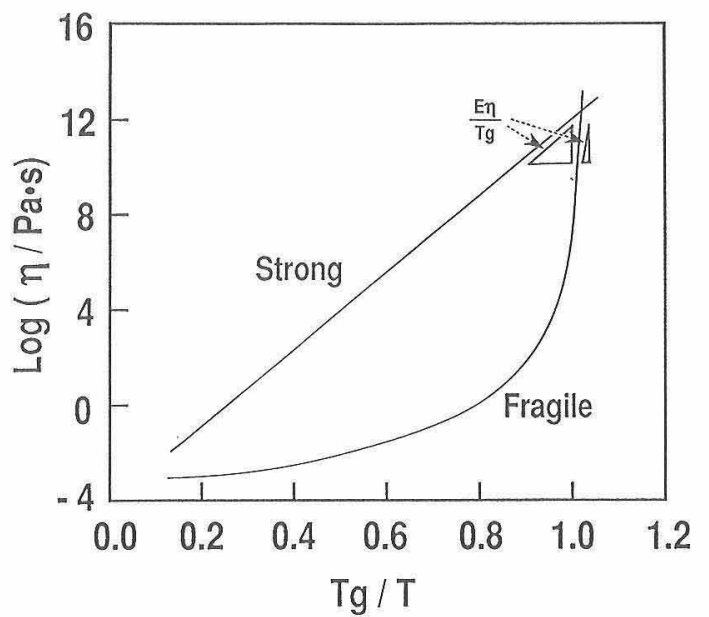

Fig. 1. Schematic illustration of temperature dependence of viscosity for strong and fragile glass-forming liquids. 
増加し, $\Delta C_{\mathrm{p}}$ と $E \eta / T_{\mathrm{g}}$ の両方の観点から fragility が増加 することが分かった。

先に述べたように, $\mathrm{AgI}-\mathrm{Ag}_{2} \mathrm{O}-\mathrm{M}_{x} \mathrm{O}_{y}\left(\mathrm{M}_{x} \mathrm{O}_{y}\right.$ は種々の酸 化物）系超イオン伝導ガラスの $\Delta C_{\mathrm{p}}$ は $\mathrm{AgI}$ 含量の増加に 伴い減少することが分かっており， $\Delta C_{\mathrm{p}}$ の観点からは $\mathrm{AgI}$ の増加とともに液体構造が fragileなものから strong なものに変化していくように見える．そこで $E \eta / T_{\mathrm{g}}$ の観 点から fragility がどのように変化するかは興味がもたれ るところであるが，このような系に対する粘度の温度依存 性についてはこれまで検討がなされていない.

本研究では, 示差走査熱量計 (DSC) と熱機械分析計 (TMA) を用いて, $\mathrm{AgI}-\mathrm{Ag}_{2} \mathrm{O}-\mathrm{M}_{x} \mathrm{O}_{y}\left(\mathrm{M}_{x} \mathrm{O}_{y}=\mathrm{B}_{2} \mathrm{O}_{3}, \mathrm{GeO}_{2}\right.$, $\left.\mathrm{P}_{2} \mathrm{O}_{5}, \mathrm{MoO}_{3}\right)$ 系超イオン伝導ガラスのガラス転移点付近 に括ける比熱変化と粘度を測定し, AgI 含量の変化に対 する $\Delta C_{\mathrm{p}}$ 及び $E \eta / T_{\mathrm{g}}$ の変化について検討し, fragility に 対して考察を行った。

\section{2. 実 験}

\section{1 ガラスの作製}

各系に対し, $\mathrm{Ag}_{2} \mathrm{O}$ と $\mathrm{M}_{x} \mathrm{O}_{y}$ のモル比を $\mathrm{Ag}_{2} \mathrm{O} / \mathrm{M}_{x} \mathrm{O}_{y}=1$ と固定し, AgI 含量を変化させた組成についてガラスを 作製した. 出発原料として, ヨウ化銀 AgI (特級), 酸化 銀 $\mathrm{Ag}_{2} \mathrm{O}$ (特級)，三酸化ホウ素 $\mathrm{B}_{2} \mathrm{O}_{3}$ (特級)，二酸化ゲ ルマニウム $\mathrm{GeO}_{2}$ (特級), リン酸二水素アンモニウム $\mathrm{NH}_{4} \mathrm{H}_{2} \mathrm{PO}_{4}$ (特級)，三酸化モリブデン $\mathrm{MoO}_{3}$ (特級) を 用いた。これらを所定の組成になるように秤量, 混合した ものを一端を封じた石英ガラス管に入れ，電気炉中500 $600^{\circ} \mathrm{C}$ 温度域で, $30 \sim 60$ 分間空気中で溶融し, 流し出し た融液を 2 枚の金属板で挟みつけるプレス急冷法により ガラスを作製した. 冷却速度は $10^{2} \sim 10^{3} \mathrm{~K} / \mathrm{s}$ 程度である. 得られた試料については X 線回折測定により, ガラスで あるか否かの判定を行った，示差走査熱量測定により，得 られたガラスのガラス転移温度 $\left(T_{\mathrm{g}}\right)$ 及びガラス転移の 際の比熱の変化量 $\left(\Delta C_{\mathrm{p}}\right)$ を見積もった. $T_{\mathrm{g}}$ と $\Delta C_{\mathrm{p}}$ の值

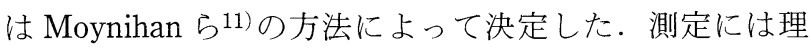
学電機製示差走査熱量計 (DSC-8230) 及びパーキンエル マー社製示差走査熱量計（DSC-7）を用いた。昇温速度 は $10 \mathrm{~K} / \mathrm{min}$ で測定した。

\section{2 粘度測定}

粘度測定は, $8 \times 3 \times 1 \mathrm{~mm}$ 程度の直方体のガラス試料に 対して, ビームベンディング法により行い, Hagy ${ }^{12)} に よ$ り導かれた粘度式を用いて種々の温度に打ける粘性係数を 算出した ${ }^{10), 13)}$. 装置はマックサイエンス社製熱機械分析 装置（TMA4000）を用いた. National Bureau of Standards の717ガラス（borosilicate glass）を標準試料に選 び，装置の校正を行った.

\section{3. 結果と考察}

図 2 は $\mathrm{AgI}-\mathrm{Ag}_{2} \mathrm{O}-\mathrm{M}_{x} \mathrm{O}_{y}\left(\mathrm{M}_{x} \mathrm{O}_{y}=\mathrm{B}_{2} \mathrm{O}_{3}, \mathrm{GeO}_{2}, \mathrm{P}_{2} \mathrm{O}_{5}\right.$, $\left.\mathrm{MoO}_{3}\right)$ 系ガラスに対しガラス転移温度 $\left(T_{\mathrm{g}}\right)$ の)組成依存 性を示したものである. $\mathrm{M}_{x} \mathrm{O}_{y}$ が $\mathrm{B}_{2} \mathrm{O}_{3}, \mathrm{GeO}_{2}, \mathrm{P}_{2} \mathrm{O}_{5}, \mathrm{MoO}_{3}$

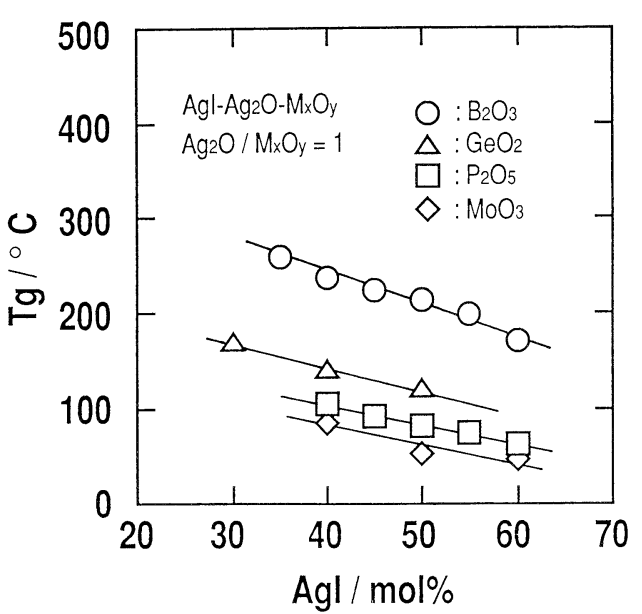

Fig. 2. Composition dependence of $T_{\mathrm{g}}$ of the $\mathrm{AgI}-\mathrm{Ag}_{2} \mathrm{O}-\mathrm{M}_{x} \mathrm{O}_{y}$ $\left(\mathrm{M}_{x} \mathrm{O}_{y}=\mathrm{B}_{2} \mathrm{O}_{3}, \mathrm{GeO}_{2}, \mathrm{P}_{2} \mathrm{O}_{5}, \mathrm{MoO}_{3}\right)$ glasses.

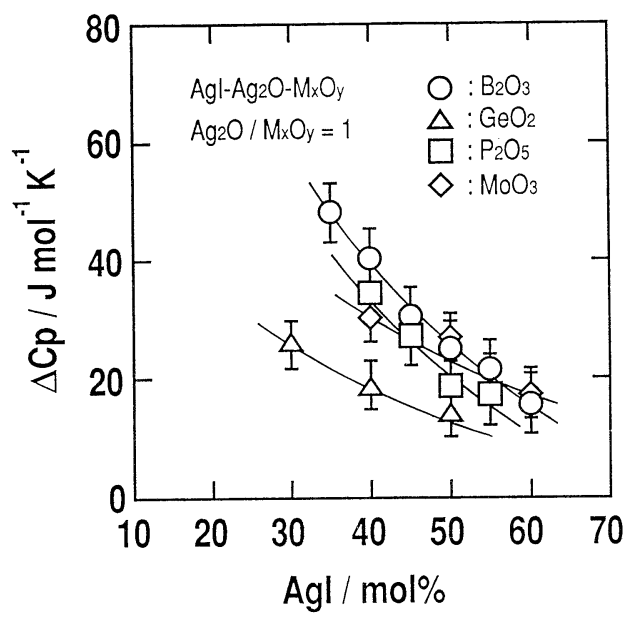

Fig. 3. Composition dependence of $\Delta C_{\mathrm{p}}$ of the $\mathrm{AgI}-\mathrm{Ag}_{2} \mathrm{O}-\mathrm{M}_{x} \mathrm{O}_{y}$ $\left(\mathrm{M}_{x} \mathrm{O}_{y}=\mathrm{B}_{2} \mathrm{O}_{3}, \mathrm{GeO}_{2}, \mathrm{P}_{2} \mathrm{O}_{5}, \mathrm{MoO}_{3}\right)$ glasses.

のいずれの系においても, AgI 含量が増加するほど $T_{\mathrm{g}}$ は 減少する傾向が見られる.これらの值はすでに以前報告し た結果4) と一致しているし，更に $\mathrm{AgI}-\mathrm{Ag}_{2} \mathrm{O}-\mathrm{B}_{2} \mathrm{O}_{3}$ 系と $\mathrm{AgI}-\mathrm{Ag}_{2} \mathrm{O}-\mathrm{P}_{2} \mathrm{O}_{5}$ 系ガラスに対するHallbrucker と $\mathrm{Johari}^{5}$ 及び Shastry と $\mathrm{RaO}^{6)}$ のデータともほぼ一致した.

図 3 は, $\mathrm{AgI}-\mathrm{Ag}_{2} \mathrm{O}-\mathrm{M}_{x} \mathrm{O}_{y}\left(\mathrm{M}_{x} \mathrm{O}_{y}=\mathrm{B}_{2} \mathrm{O}_{3}, \mathrm{GeO}_{2}, \mathrm{P}_{2} \mathrm{O}_{5}\right.$, $\mathrm{MoO}_{3}$ ) 系ガラスに対しガラス転移温度での比熱の変化量 $\left(\Delta C_{\mathrm{p}}\right)$ の組成依存性を示したものである. $\mathrm{M}_{x} \mathrm{O}_{y}$ が $\mathrm{B}_{2} \mathrm{O}_{3}$, $\mathrm{GeO}_{2}, \mathrm{P}_{2} \mathrm{O}_{5}, \mathrm{MoO}_{3}$ のいずれの系においても, $\mathrm{AgI}$ 含量の 増加に伴い $\Delta C_{\mathrm{p}}$ は減少する傾向がみられる. $\Delta C_{\mathrm{p}}$ の観点 からは fragility が小さくなっているように見える. 今回 得られた $\mathrm{AgI}-\mathrm{Ag}_{2} \mathrm{O}-\mathrm{P}_{2} \mathrm{O}_{5}$ 系ガラスに拈ける比熱の変化量 $\left(\Delta C_{\mathrm{p}}\right)$ は Hallbrucker らのデータ5) とほぼ一致した.

図 4 は $50 \mathrm{AgI} \cdot 25 \mathrm{Ag}_{2} \mathrm{O} \cdot 25 \mathrm{M}_{x} \mathrm{O}_{y}\left(\mathrm{M}_{x} \mathrm{O}_{y}=\mathrm{B}_{2} \mathrm{O}_{3}, \mathrm{GeO}_{2}\right.$, $\mathrm{P}_{2} \mathrm{O}_{5}, \mathrm{MoO}_{3}$ ) 系ガラスの粘度の温度依存性を示したもの である.いずれの系においても測定温度範用内での粘度は $10^{8} \sim 10^{11} \mathrm{~Pa} \cdot \mathrm{s}$ の值をとり, このような比較的狭い温度域 では $\log \eta$ と $1 / T$ の間に直線関係が得られた。この直線 


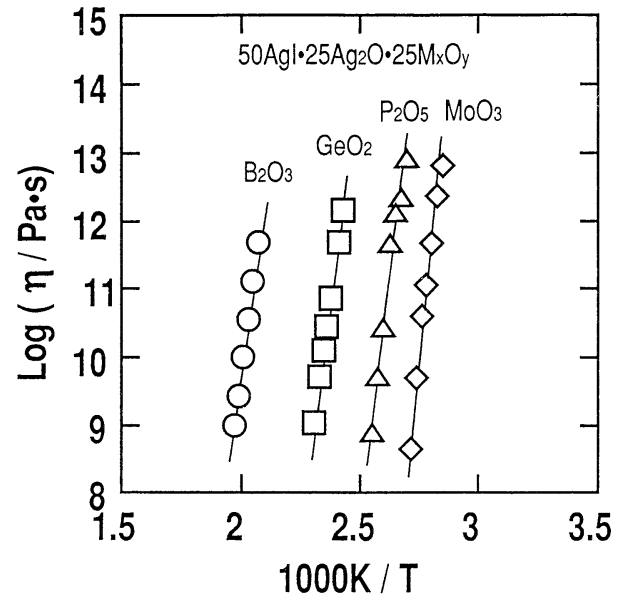

Fig. 4. Temperature dependence of viscosity of the 50AgI. $25 \mathrm{Ag}_{2} \mathrm{O} \cdot 25 \mathrm{M}_{x} \mathrm{O}_{y}\left(\mathrm{M}_{x} \mathrm{O}_{y}=\mathrm{B}_{2} \mathrm{O}_{3}, \mathrm{GeO}_{2}, \mathrm{P}_{2} \mathrm{O}_{5}, \mathrm{MoO}_{3}\right)$ glasses in the temperature range at around $T_{\mathrm{g}}$.

の傾きを用いて，ガラス転移温度域における粘性流動に対 する見掛けの活性化エネルギー（En）を算出した.

図 5 は, $\mathrm{AgI}-\mathrm{Ag}_{2} \mathrm{O}-\mathrm{M}_{x} \mathrm{O}_{y}\left(\mathrm{M}_{x} \mathrm{O}_{y}=\mathrm{B}_{2} \mathrm{O}_{3}, \quad \mathrm{GeO}_{2}, \mathrm{P}_{2} \mathrm{O}_{5}\right.$, $\left.\mathrm{MoO}_{3}\right)$ 系ガラスに対し $E \eta$ の組成依存性を示したもので ある. Enは $\mathrm{B}_{2} \mathrm{O}_{3}$ 系の場合 $410 \sim 490 \mathrm{~kJ} / \mathrm{mol}$ の值をと り, $\mathrm{GeO}_{2}$ 系では $480 \sim 490 \mathrm{~kJ} / \mathrm{mol}, \mathrm{P}_{2} \mathrm{O}_{5}$ 系では500〜530 $\mathrm{kJ} / \mathrm{mol}, \mathrm{MoO}_{3}$ 系では $480 \sim 540 \mathrm{~kJ} / \mathrm{mol}$ の值をとった. $E \eta$ は $\mathrm{M}_{x} \mathrm{O}_{y}$ が $\mathrm{B}_{2} \mathrm{O}_{3}, \mathrm{GeO}_{2}, \mathrm{P}_{2} \mathrm{O}_{5}, \mathrm{MoO}_{3}$ の順に大きくなる ことが分かった。をた，いずれの系に扔いても $\mathrm{AgI}$ 含量 が増加するほどEは減少する傾向を示した。

図 6 は, $\mathrm{AgI}-\mathrm{Ag}_{2} \mathrm{O}-\mathrm{M}_{x} \mathrm{O}_{y}\left(\mathrm{M}_{x} \mathrm{O}_{y}=\mathrm{B}_{2} \mathrm{O}_{3}, \mathrm{GeO}_{2}, \mathrm{P}_{2} \mathrm{O}_{5}\right.$, $\left.\mathrm{MoO}_{3}\right)$ 系に対し， $E \eta / T_{\mathrm{g}}$ の組成依存性を示したものであ る. $E \eta / T_{\mathrm{g}}$ は $\mathrm{M}_{x} \mathrm{O}_{y}$ が $\mathrm{B}_{2} \mathrm{O}_{3}, \mathrm{GeO}_{2}, \mathrm{P}_{2} \mathrm{O}_{5}, \mathrm{MoO}_{3}$ の順に大 きくなっており，この順に $E \eta / T_{\mathrm{g}}$ の観点から fragility が 大きくなると考えられる.

一方，いずれの系に打いても $\mathrm{AgI}$ 含量の変化に伴う $E \eta / T_{\mathrm{g}}$ の変化はほとんぞみられず, $E \eta / T_{\mathrm{g}}$ の観点から fragility は AgI 含量によってほとんど変化しないことが 分かった．この結果から, $\mathrm{AgI}$ 含量の増加に伴う $\Delta C_{\mathrm{p}}$ の 減少は fragilityの低下ではなく, 他の要因が関係してい るものと考えられる.

AgI 系超イオン伝導ガラスの構造解析から，AgI成分 は酸化物ガラスのネットワークの形成には関与せず，微小 な $\mathrm{AgI}$ クラスターとして存在することが指摘されてい $3^{1), 14) \sim 17)}$ 。例えば, Börjesson らは AgI- $\mathrm{Ag}_{2} \mathrm{O}-\mathrm{P}_{2} \mathrm{O}_{5}$ 系 の Brillouin 散乱を測定し，マイクロ波領域での音速は $\alpha$ $\mathrm{AgI}$ 結晶の值の室温への外挿値と一致することを見いだ し， $\alpha-\mathrm{AgI}$ 類似の局所的クラスターの存在を支持した ${ }^{17)}$. もし，ガラス転移の際のエンタルピー変化が，酸化物ガラ スのネットワーク部分のみに関与し，AgIのクラスター 部分には関与していないと考えると, AgI 含量の増加に 伴う $\Delta C_{\mathrm{p}}$ の減少は, 酸化物ガラスのネットワーク部分が 減少するために見られる現象と考えられる。このような現 象は，ガラスの中に部分的に結晶が析出したような系で，

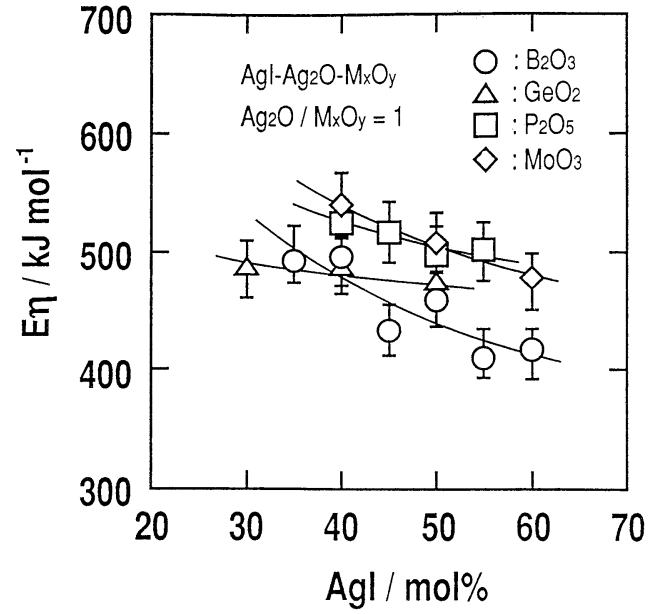

Fig. 5. Composition dependence of activation energy for viscous flow $E \eta$ of the AgI- $\mathrm{Ag}_{2} \mathrm{O}-\mathrm{M}_{x} \mathrm{O}_{y}\left(\mathrm{M}_{x} \mathrm{O}_{y}=\mathrm{B}_{2} \mathrm{O}_{3}, \mathrm{GeO}_{2}, \mathrm{P}_{2} \mathrm{O}_{5}, \mathrm{MoO}_{3}\right)$ glasses.

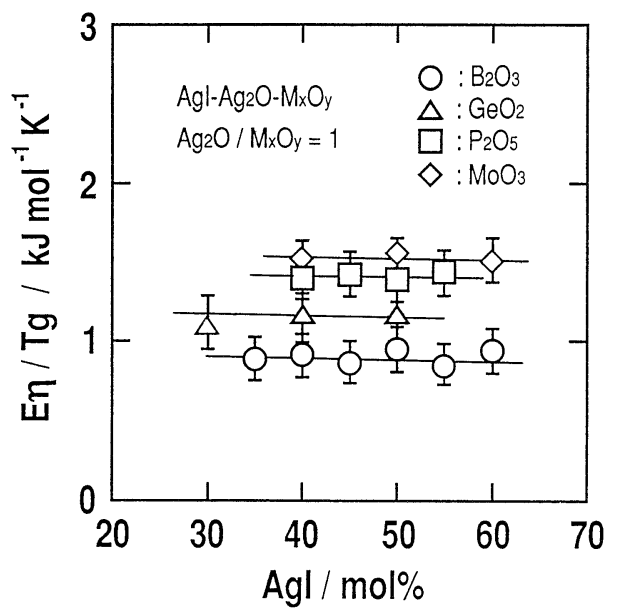

Fig. 6. Composition dependence of $E \eta / T_{\mathrm{g}}$ of the $\mathrm{AgI}-\mathrm{Ag}_{2} \mathrm{O}-$ $\mathrm{M}_{x} \mathrm{O}_{y}\left(\mathrm{M}_{x} \mathrm{O}_{y}=\mathrm{B}_{2} \mathrm{O}_{3}, \mathrm{GeO}_{2}, \mathrm{P}_{2} \mathrm{O}_{5}, \mathrm{MoO}_{3}\right)$ glasses.

析出結晶が増加するほどガラス転移の際の $\Delta C_{\mathrm{p}}$ が減少す る現象 5 と類似のものである.

更に, $E \eta / T_{\mathrm{g}}$ も $\mathrm{AgI}$ 含量の変化に対してほとんど変化 していないことから，この值も酸化物ガラス部分に主とし て関係していると考えら机るが， $\Delta C_{\mathrm{p}}$ のように酸化物ガ ラスのネットワークを形成する部分の量に依存する示量的 なパラメーターではなく，示性的なパラメーターであると 考えられる．以上のことから，これらの系では fragility は主として微小な $\mathrm{AgI}$ クラスターを除く酸化物ガラス部 分の影響を受け, AgI 含量によってはほとんど変化しな いと結論することができる.

\section{4. 結 論}

$\mathrm{AgI}-\mathrm{Ag}_{2} \mathrm{O}-\mathrm{M}_{x} \mathrm{O}_{y}\left(\mathrm{M}_{x} \mathrm{O}_{y}=\mathrm{B}_{2} \mathrm{O}_{3}, \mathrm{GeO}_{2}, \mathrm{P}_{2} \mathrm{O}_{5}, \mathrm{MoO}_{3}\right)$ 系 超イオン伝導ガラスのガラス転移点付近における粘度と $\Delta C_{\mathrm{p}}$ を測定したところ, $\mathrm{AgI}$ 含量の増加に伴い $\Delta C_{\mathrm{p}}$ は単 調に減少するのに対し,$E \eta / T_{\mathrm{g}}$ はほとんど変化しないこ 
とが分かった。加えた AgI 成分が酸化物ガラスのネット ワークの形成には関与せず，微小な AgI クラスターとし て存在し，このクラスター部分がガラス転移の際のエンタ ルピー変化に関与していないと考えると, $\mathrm{AgI}$ 含量の増 加に伴う $\Delta C_{\mathrm{p}}$ の減少はガラスのネットワーク部分の量が 減少するために起こるものと考えられる. また, $E \eta / T_{\mathrm{g}}$ が AgI 含量に対してほとんど変化していないことは, $E \eta / T_{\mathrm{g}}$ も主として酸化物ガラス部分に支配されるが, $\Delta C_{\mathrm{p}}$ のように示量的なバラメーターではなく，示性的な パラメーターであることを意味している. 結局, $E \eta / T_{\mathrm{g}}$ の観点からは fragility は AgI 含量によってほとんど変化 せず，それをもとに考えると， $\Delta C_{\mathrm{p}}$ の観点からも fragility は大きくは変化していないものと考えられる.

\section{文献}

1) T. Minami, J. Non-Cryst. Solids, 73, 273-83 (1985).

2) D. Ravaine, J. Non-Cryst. Solids, 73, 285-303 (1985).

3) K. Pathmanathan, R. Mlcak and G. P. Johari, Phys. Chem. Glasses, 30, 180-85 (1989).

4) T. Minami, Y. Ikeda and M. Tanaka, J. Non-Cryst. Solids,
52, 159-69 (1982).

5) A. Hallbrucker and G. P. Johari, Phys. Chem. Glasses, 30, 211-14 (1989).

6) M. C. R. Shastry and K. J. Rao, Solid State Ionics, 37, 17-29 (1987).

7) M. D. Ingram, J. M. Hutchinson and A. J. Pappin, Phys. Chem. Glasses, 32, 121-28 (1989).

8) C. A. Angell, J. Non-Cryst. Solids, 73, 1-17 (1985).

9）岸岡 昭, 宮石徹, 木下真喜雄, 割協, 87, 422-29 (1979).

10）李 相基, 辰巳砂昌弘, 南 努, J. Ceram. Soc. Japan, 101, 1018-20 (1993).

11) C. T. Moynihan, A. J. Easteal and M. A. Debolt, J. Am. Ceram. Soc., 59, 12-16 (1976).

12) H. E. Hagy, J. Am. Ceram. Soc., 46, 93-97 (1963).

13) M. Tatsumisago, B. L. Halfpap, J. L. Green, S. M. Lindsay and C. A. Angell, Phys. Rev. Lett., 64, 1549-52 (1990).

14) J. P. Malugani and R. Mercier, Solid State Ionics, 13, 293-99 (1982).

15) M. Tachez, R. Mercier, J. P. Malugani and P. Chieux, Solid State Ionics, 25, 263-70 (1987).

16) A. Fontana, F. Rocca and A. Tomasi, J. Non-Cryst. Solids, 123, 230-33 (1990).

17) L. Börjesson, S. W. Martin, L. M. Torell and C. A. Angell, Solid State Ionics, 18-19, 431-36 (1986). 